\title{
Horizontal-flow (HF) constructed wetlands for winery wastewater treatment: A review
}

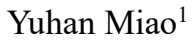 \\ ${ }^{1}$ Binghamton University, New York, United State
}

\begin{abstract}
The winery wastewater starts to become a threaten to environment and ecosystem. Because constructed wetland has advantages of low cost, low maintaining fee and energy saving, there are more researchers use this technology to purify the winery wastewater. In this article, the horizontal flow constructed wetland will be mainly focused. By using this method, the N, P, organic matter, and other pollutants will be efficiently removed and reused in other phase, such like agricultural activities. The constructed wetland can also supply itself. By transfer the nutrition matter from wastewater and support its' own plants' energy.
\end{abstract}

\section{Introduction}

The overdevelopments of winery industrial factories bring more profit to human. Also, the outpouring of Winer wastewater will be increased in the same time. Meanwhile the high cost of processing winery wastewater fee or incorrect dealing ways, and other different factors make the winery wastewater filled into receiving water body without appropriate treating.[1] So that, the winery wastewater will cause influencing on the nature and become to be a main threaten for the local environment and ecosystem. The main causing reason is that the winery wastewater normally will bring a huge amount of nutrition contends like carbon, nitrogen, phosphorus, and organisms. The $\mathrm{pH}$ level of the waster will also be varied seasonally. The living habits and environment will totally be influenced by the winery wastewater pollution. So that, the local environment will get destroyed.

There were different ways to deal with winery wastewater. Commonly, it can be including in chemical, physical and biological. The chemical and physical are the most fundamental ways that be used to deal with winery wastewater, because they are normally cheap and easier. However, in some cases they cannot totally remove the pollutant or will cause another pollution to the environment. So, the biological will be a certain stable method to process wastewater.

The biological composed technologies can be more efficiency on removing organisms and ammonia. However, the biological processing technologies will also cause several problems. For example, it will cause taking large spaces, difficulties on managing and maintaining, unstable effluent and other problems. So, the topic of "How to make traditional winery wastewater process become to more efficiently, scientifically and reasonably" will be a new challenge to humans.

Constructed wetland $(\mathrm{CW})$ is the artificial intervention of natural wetland.[2] For now, it is primarily used in processing domestic sewage and industrial wastewater. The main functions of $\mathrm{CW}$ are based on adsorption of matrix, absorption of $\mathrm{CW}$ plants, assimilation of microorganism and the interactions of them. So, the N, P, organisms' organic matter and other pollutants will be removed.

CW also has different types, such like horizontal-flow, perpendicular-flow, tidal etc. Basically, its type will decide the water current of CW. CW is not be widely used in the current society, but it already showed its benefits to human the nature and ecosystem. It certainly will be one of the best ways on processing the winery wastewater in the future when this technology gets more improvement.

This article will briefly introduce the researching on progress of treating efficiency of winery wastewater on horizontal-flow CW. The structure of horizontal-flow CW as figure1. This work will provide useful guidance for researchers working in the how the removal rates of organisms and other nutritional contents by improve the CW treatment.

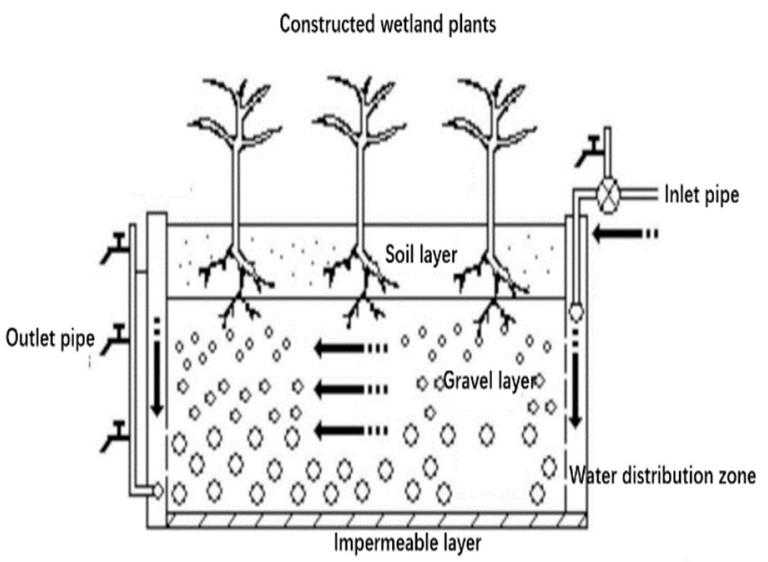

Fig. 1. The structure of horizontal-flow CW. 


\section{Winery wastewater treatment with horizontal-flow (HF) constructed wetlands}

De la Varga and his partners did a long-term experiment which is observing the efficiency of purifying pollute in the winery wastewater under different depth.[3]The total suspended solids (TSS) are efficiently removed in every three horizontal-flow (HF) positions. In all those three HF positions, the wastewater concentrations below $44 \mathrm{mg} / \mathrm{L}$, which the average concentration is $17 \mathrm{mg} / \mathrm{L}$, and the removal efficiency is $74 \%$. The removal efficiency of chemical oxygen demand (COD) and biological oxygen demand (BOD) is around $60-80 \%$, however, with the surface loading rate (SLR), the removal efficiency decrease.

Compare with the deeper HF CW which $0.6 \mathrm{~m}$ depth, the shallower HFCW which $0.3 \mathrm{~m}$ depth is has showed lower efficiency on dealing with pollute at the higher influent concentration. If the influent of BOD5 higher to around 400-600 mg/L, the removal percentage has sharply decreased in every HF CW positions, and the surface removal rate (SRR) has got maximum point at 7-8 $\mathrm{g}$ BOD $5 / \mathrm{m}^{\wedge} 2 \mathrm{~d}$; Also, the SLR would go to relative low point which about $10-20 \mathrm{~g} \mathrm{BOD} 5 / \mathrm{m}^{\wedge} 2 \mathrm{~d}$. At the greater SLR the net SRR would be decreased. With SLR from low to mid-level, the COD and BOD5 removal in HF position followed the first order kinetic model. The $\mathrm{Ka}$ values of BOD5 removal is around $0.028-0.32 \mathrm{~m} / \mathrm{d}$.

Because in the past 30 years, the winery factory in rural of California was increasing, the winery wastewater was also getting increased. Mark E Grismer with his group member did an experiment to determine the efficiency of purifying pollute with the winery wastewater construct wetland. [4]

The experiment collected data from fall which had heavy load and the spring which had less burden than fall. The advantages of this method are low coast and ability to deal with variable organic productions from the winery wastewater. However, because of possible effects on the downstream organisms, lignin, tannin and other polyphenolics. There should be some unusual further treatments to be existed. There was an evaluation of the methods to treat the degraded wetland due to winery water. By the simple bench scale reactors, the removal rate of COD and tannin are 59-72\% and 54-58\%. Meanwhile, the Hopland CW also showed this COD and tannin removal rates are closed, which are respective $49-79 \%$ and $46-78 \%$. The removal rate for $\mathrm{CW}$ will be greater when in noncrush period in the spring. The Glen Ellen CW had less loading rate and more hydraulic retention time (HRT) than the Hopland CW, however, it had almost perfect COD removal rate which around $800 \mathrm{mg} / \mathrm{L}$ to $5 \mathrm{mg} / \mathrm{L}$ in its' recirculation system. That shows the system of Glen Ellen could have a great efficiency on treating on winery wastewater if the processing is correct.

The lab experiment's wastewater COD strength is greater than full scale CW, however, their tannin loading, and their removal rate are very closed. Even the benchscale reactor has a shorter HRT, but the tannin decay rate in those systems are similar which around $0.3 \mathrm{~d}-1$.
In their experiment, the Hopland $\mathrm{CW}$ had shortcircuiting before crush-season measurement, so they did not have enough data to find the potential efficiency of the purifying pollute in this $\mathrm{CW}$. So, in the crush season, under the non-broken $\mathrm{CW}$ situation, the removal efficiency is uncertain, even it clearly showed the result that the removal rate is great during the spring.

The HRT was around 1 hour when it was in the crush season, but it will be almost 5 days during non-crush season. However, under this kind of situation, the $\mathrm{CW}$ still made inlet COD decreased $50 \%$, and reduce other pollute by $20-30 \%$ in crush season.

$\mathrm{J}$ Mena and the partners did an experiment to discover how does polyphenols influence synthetic winery waste water with different plants and horizontal subsurface flow constructed wetland (HSSF-CWs) . [5]

They used simulated environment with low-loaded wastewater and HSSF-CWs were used in this experiment. The duration of this experiment is 4 months, and used 4 different plants which are Phragmites australis on the second HSSF-CW, Lythrum salicaria on the third HSSFCW3, Cladium mariscus on the fourth HSSF-CW, and Iris pseudacorus on the last HSSF-CW. The first HSSF-CW did not have any plants on it.

The final result of this experiment showed the removal efficiency of pollute which influenced those plants is very high and significant. Especially for the plants which have higher growth ability, such like Phragmites australis, Lythrum salicaria, and Iris pseudacorus. Those plants helped to enhance ability removing of nutrition, but effluence sulphate anaerobic reduction negatively. However, those high growing plants were only working on removal of N-NH4+ efficiently. If only add polyphenols with a low concentration which around $13 \mathrm{mg} / \mathrm{L}$, it will not cause negative influence on COD, total nitrogen (TN), $\mathrm{N}-\mathrm{NH} 4+$. Whereas low concentration polyphenols can influence SO4 2- significantly. In a conclusion, the polyphenols can be removed by the plants' treatments nearly complete.

Johnson B Melody did a review with his partner to estimate the efficiency of winery wastewater (WINERY WASTEWATER) treating system in Niagara, Ontario, Canada.[6]There was a lot of different treatments which has been used in this region. With their analyzation for around $45 \%$ winery factory in Niagara region which is 53 factories, the most frequent treatment is the combination of primary settling and CWs. This combination can give both physical and chemical influence on the WINERY WASTEWATER from surfaces of river or underground water. The $\mathrm{CW}$ method was very useful due to its flexibility on the designing of it modular setting. CW method also can change the substrate and liquid level. It can be worked under aerobic, anoxic and anaerobic, environment. This flexible characteristic made $\mathrm{CW}$ can be applied in complex $(>10 \mathrm{~m} 3 / \mathrm{d})$ to simple $(\leq 10 \mathrm{~m} 3 / \mathrm{d})$ environment.

CW works efficiently for the total removing of BOD, COD and TSS, and improve removal efficiency of total nitrogen in the WINERY WASTEWATER. The CW method did not work well on removing of total phosphorus; however, this kind of wastewater can be reused on irrigation and reduce the demand of fertilizer. 
Anaerobic co-digestion method is thew most useful treatment on dealing with WINERY WASTEWATER, and it can cause huge amount of biogas $(80 \mathrm{~m} 3$ biogas per 1 $\mathrm{m} 3$ WINERY WASTEWATER) which is also useful to human. Even though there were several issues to trouble with co-treatment on WINERY WASTEWATER, such like limiting of oxygenation, changing effluent quality, and decreased sludge settleability.

Shepherd Heather and his partners tried to find the efficiency of treating high concentration WINERY WASTEWATER on subsurface-flow CW.[7]The experiment group used a pilot-scale subsurface-flow CW which had $6.1 \mathrm{~m}$ length, $2.4 \mathrm{~m}$ width and $1.2 \mathrm{~m}$ depth. The treated WINERY WASTEWATER is from a medium size vine factory which produced 2 million cases per year. The biologic load for these flow rates of the WINERY WASTEWATER 80 to $170 \mathrm{~m} 3 / \mathrm{d}$ is 600 to $45,000 \mathrm{mg}$ $\mathrm{COD} / \mathrm{L}$. With the pre-treatment of sand filter, the removing of $\mathrm{CW}$ for COD is $98 \%$, and $97 \%$ for TSS. This treatment also could remove total phenols, $98.5 \%$ sulphide, $78.2 \%$ nitrogen and other limited maters.

In this article, Grismer and his partners were trying to define the hydraulic characteristics of a subsurface flow (SSF) CW by bromide. [8]Because of the uncertain internal detention time which is caused by the different porous-media hydraulic characteristics. Bromide is a great tracer in this experiment due to its non-absorbed characteristic and cheap.

In Mulidzi's article, he did a research on finding the efficiency of treating winery wastewater (WINERY WASTEWATER) by CW during a short remining period. [9]

During a short remaining time of a week which the CW will deal with 8,100 litters of WINERY WASTEWATER per day, he got the average removal of COD is $60 \%$. Compare with the $80 \%$ removal of COD which during the 14 days retention, the 7 days retention which has $60 \%$ removal is more important, if thew winery factories want to treat more WINERY WASTEWATER. Meanwhile, he got the information that the removal efficiency will be the lowest in July to September (Figure 1). The reason to cause of this kind of phenomenon maybe is the wastewater was emitted very rapidly, and it will cause the changing on organism's' feature and amount.

The vegetations from $\mathrm{CW}$ can absorb the nutrient of WINERY WASTEWATER. The microorganisms also can be help on depositing organic matters and the removing pollutes. The efficiency of microorganism's purify can be mostly $90 \%$, and plants can do $7 \%-10 \%$ on the same work. When those plants decayed, the microorganisms can take them as food. The chosen of diversity of plants' species is also important, and it can help the plants avoid several negative influences such as insect diseases. The aquatic plants took great percentage of living plants in wetland environment. Aquatic plants are very helpful on absorbing pollutants from WINERY WASTEWATER and can be nutrition to supply other chemical or physical removal processes. Also, the extra plant's deposition or growth materials can be keep using in the wetland cleaning system. The wetland also has less maintaining fee than other kinds of cleaning systems.

In Mulidzi's article, he tried to figure out how can purified WINERY WASTEWATER will be used on the commercial crop productions.[10] In 2002, there was a $\mathrm{CW}$ built with the scale of $45 \mathrm{mx} 4 \mathrm{mx} 1 \mathrm{~m}$ at Goudini. The average COD for the winery factory on this $\mathrm{CW}$ is $14,000 \mathrm{mg} / 1$. After the CW treatment, the output processed water has the COD of $500 \mathrm{mg} / \mathrm{l}$, which the removal rate is greater than $90 \%$. In the result at 2004-2005, the data proved the COD can be efficiently removed from the $\mathrm{CW}$. In the same year, the average removal rate in winter is $83 \%$, and $80 \%$ in the summer. In the result of $2005-2006$, the average total removal for this year is $82 \%$. The winter removal is $88 \%$ and $77 \%$ in the summer. On the phase of dealing with the elements, Sodium, potassium, phosphorus, and calcium can be removed by certain amounts. The $\mathrm{pH}$ level of this wastewater will also be neutralized and get to be $\mathrm{pH}$ level around 6.5 to 7 . Bulrush has more efficiency on removal of sodium than the cattails The maintenance status was just be same as his previous research [9], the deposition or decayed parts of the plants can be reused in the system. The only thing needs to be concerned is cleaning the extra plants and cutting down the plants which have the certain length.

The processed wastewater was used to irrigate four compared groups of cabbage. They are: group 1 with pure irrigation water with fertilizer, group 2 with pure irrigation water without fertilizer, group 3 with wastewater-based irrigation water with fertilizer, and the group 4 with wastewater-based irrigation water without fertilizer. The result showed that the processed wastewater can be used to irrigate the crops and change the nutrition status of the soil.

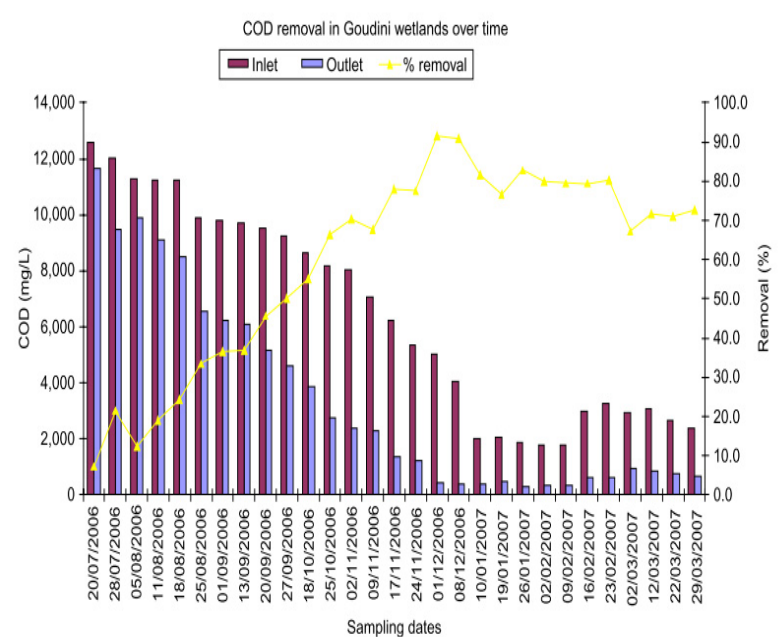

Fig. 2. The value and removal rate of COD during the whole year with the 7-days retention was applied. [9]

\section{Conclusion}

In a conclusion, the past research show that the horizontalflow CW has impressive efficiency on dealing the WINERY WASTEWATER and become to a dependable technology on purifying wastewater. Especially, removing of $\mathrm{N}, \mathrm{P}$ and $\mathrm{C}$ is very significant by horizontal-flow $\mathrm{CW}$. The decreasing rate of COD and BOD can reach to $60 \%$ $80 \%$. Organic matter or organisms always be the main content in winery wastewater, and horizontal-flow $\mathrm{CW}$ can efficiently work on removing it and put it reuse on 
maintaining $\mathrm{CW}$ itself. The basic functions of $\mathrm{CW}$ always have adsorption of matrix, absorption of $\mathrm{CW}$ plants, assimilation of microorganism. Those functions and their interactions support the processing of purifying and help the processed water to be recycle in $\mathrm{CW}$ environment or other plantation as nutritional irrigation. Compare to other traditional method, $\mathrm{CW}$ has low cost on running, maintaining, and operating. However, it still has disadvantages. Such like the large taking spaces, pollutant blockages or high building fee etc. Whereas most of them have solutions. To the large taking spaces, most $\mathrm{CW}$ were built at the locations where will not influence human's life and can be positive for several organisms to be their habitats. Even the CW treatment is not perfect, but it still has lots of possibility to be improved. In the future, the $\mathrm{CW}$ treatment can be more efficiently on dealing with other specific pollutants by finding the most suitable flow direction or species of plants. Not to mention CW treatment is one of the sustainable, green treatment on wastewater purifying. So, the future of $\mathrm{CW}$ treatment is very expectable and bright.

\section{References}

1. Y.Y. Zhang Xiaofei, Treatment process for wastewater from Moutai - flavor liquor brewing. Environmental Protection and Technology, 22,No.2 (2016)

2. Y. Liang, et al., Constructed wetlands for saline wastewater treatment: A review. Ecological Engineering, 98 (2017)

3. D. De la Varga, I. Ruiz, and M. Soto, Winery Wastewater Treatment in Subsurface Constructed Wetlands with Different Bed Depths. Water, Air, \& Soil Pollution, 224,4 (2013)

4. M.E. Grismer, M.A. Carr, and H.L. Shepherd, Evaluation of Constructed Wetland Treatment Performance for Winery Wastewater. Water Environment Research, 75,5 (2003)

5. J. Mena, et al., Influence of polyphenols on lowloaded synthetic winery wastewater constructed wetland treatment with different plant species. Canadian Journal of Civil Engineering, 36,4 (2009)

6. M.B. Johnson, and M. Mehrvar, Winery wastewater management and treatment in the Niagara Region of Ontario, Canada: A review and analysis of current regional practices and treatment performance. The Canadian Journal of Chemical Engineering, 98,1 (2020)

7. H.L. Shepherd, M.E. Grismer, and G. Tchobanoglous, Treatment of High-Strength Winery Wastewater Using a Subsurface-Flow Constructed Wetland. Water Environment Research, 73,4 (2001)

8. M.E. Grismer, M. Tausendschoen, and H.L. Shepherd, Hydraulic Characteristics of a Subsurface Flow Constructed Wetland for Winery Effluent Treatment. Water Environment Research, 73,4 (2001)
9. A.R. Mulidzi, Winery and distillery wastewater treatment by constructed wetland with shorter retention time. Water Science and Technology, 61,10 (2010)

10. A.R. Mulidzi, Winery wastewater treatment by constructed wetlands and the use of treated wastewater for cash crop production. Water Science and Technology, 56,2 (2007) 